\title{
LA AUTONOMÍA LOCAL DEVALUADA: La dudosa «racionalidad» de la Ley 27/2013, de 27 de diciembre, de racionalización y sostenibilidad de la Administración local
}

\author{
OCTAVIO SALAZAR BENÍTEZ \\ Profesor Titular de Derecho Constitucional \\ Universidad de Córdoba
}

\section{SUMARIO}

I. Introducción: la frágil garantía de la autonomía local.

II. Más sostenibilidad que racionalización: los objetivos de la reforma.

III. La reordenación de las competencias municipales.

IV. El fortalecimiento de las diputaciones provinciales.

V. Otras medidas de supuesta racionalización.

VI. Conclusiones.

\section{INTRODUCCIÓN: LA FRÁGIL GARANTIÍA DE LA AUTONOMÍA LOCAL}

Durante estos años de vigencia del texto constitucional la autonomía local ha sido una suerte de «bella durmiente» en el marco de una estructura territorial marcada por el protagonismo y las tensiones derivadas del reconocimiento del derecho a la autonomía de las nacionalidades y regiones ${ }^{1}$. De hecho, fue precisamente en el marco de las reformas estatutarias llevadas a cabo en la VIII Legislatura cuando los entes locales recuperaron una cierta entidad en el debate territorial, si bien es cierto que situados en esa frágil protección de su autonomía que deriva de la confluencia sobre ellos de dos tutelas, la estatal y la autonómica. En la práctica, la consecuencia real de

1 Salazar Benítez, O., «La autonomía local en serio: la bella durmiente... 30 años después», Treinta años de Constitución, García Roca, J. y Alberti, E. (coords.), Tirant lo Blanch, Valencia, 2010, pp. 191-221. 
esas reformas no fue tanto una mayor garantía de la autonomía local sino más bien una evolución de ese «régimen bifronte» (STC 84/1982) hacia una mayor «interiorización» de los municipios y provincias en las Comunidades Autónomas respectivas².

Este proceso sin embargo no ha resuelto satisfactoriamente los dos principales problemas que continúan aquejando a nuestros entes locales: de una parte, la carencia de un marco competencial propio, estando su ámbito de actuación condicionado por lo que determina el legislador sectorial; de otra, el predominio de la financiación condicionada que ha pervertido en buena medida la actuación de los municipios españoles. Ello ha dado lugar a que en la práctica se haya consolidado «un gobierno local de baja calidad, cautivo del corto plazo y sin horizonte temporal para proyectos estratégicos», además de en permanente contradicción con el «principio de subsidiariedad» ${ }^{3}$. Ello a su vez se ha traducido en una frágil garantía del carácter político de la autonomía local, el cual deriva de la conexión entre los principios de «autonomía» y «democrático», tal y como se reconoce en el art. 3 de la Carta Europea de Autonomía Local (CEAL). Dos principios que confluyen en la configuración de un órgano legitimado democráticamente, con capacidad para adoptar decisiones propias e independientes respecto a otros entes de categoría superior, así como para ejecutarlas. La autonomía local implica pues capacidad de indirizzo político-administrativo, de acción de gobierno, de diseño y ejecución de políticas propias ${ }^{4}$.

La progresiva interiorización autonómica de los entes locales se ha ido produciendo sin que en paralelo se hubiera llevado a cabo una reforma sustantiva de la Ley 5/1985, de 2 de abril, reguladora de las bases de régimen local (en adelante, LBRL), la cual, pese a haber cumplido inicialmente la función de concretar la «garantía constitucional» de la autonomía local, hace años que demuestra su ineficacia frente a una realidad territorial y política que la ha desbordado5. Todo ello sin perder de vista el todavía abierto debate jurídico en torno a la amplitud del mismo concepto de «bases» y al débil sostén constitucional que supone el art. 149.1.18 como justificación de la exhaustiva competencia estatal sobre el régimen local, así como las dificultades que provoca el fragmentado y heterogéneo mapa municipal español ${ }^{6}$. Ante este panorama,

2 En este sentido, son los Estatutos catalán y andaluz los que apostarían más radicalmente por esta «interiorización». Sirva como ejemplo la definición competencial que realiza la LO 2/2007, de 19 de marzo, de reforma del Estatuto de Autonomía de Andalucía en su artículo 60, así como las previsiones contenidas en el Título III dedicado a la «Organización territorial de la Comunidad Autónoma».

3 Zafra Víctor. M. «Autonomía local en el Estado autonómico», en Rodríguez-Vigil Rubio, J. L. y Fernández Llera, R. (coord.), Crisis de los Ayuntamientos, crisis de la democracia, Real Instituto de Estudios Asturianos, Oviedo, 2013, p. 556.

4 Así se subraya por ejemplo en el art. 4.3 de la Ley 5/2010, de 11 de junio, de Autonomía Local de Andalucía (LAULA), en la que se deja muy claro que «al amparo de la autonomía local que garantiza esta ley, y en el marco de sus competencias, cada entidad local podrá definir y ejecutar políticas públicas propias y diferenciadas».

5 Sólo como consecuencia del denominado Pacto Local de 1996 en el año 1999 se llevaron a cabo reformas sustantivas del régimen local y que afectaron no sólo a la LBRL, sino también a otras leyes como la LOTC y la LOREG. Sin embargo, ni siquiera llegó a debatirse el Anteproyecto de Ley básica de Gobierno Local que con base en el denominado Libro blanco sobre la reforma del gobierno local, presentó el Ministerio de Administraciones Públicas en el año 2005.

6 La crisis económica ha acentuado el debate en torno al mapa municipal español, el cual está compuesto por una gran mayoría de pequeños municipios con muchas dificultades de gestión. Esta situación exige un 
que venía reclamando desde hace años una reforma en serio del régimen local, «resulta desolador comprobar que el gobierno local solo recibe atención política con motivo de la crisis económica» ${ }^{7}$. Una atención que se ha traducido en una reforma legislativa que deja sin resolver los grandes problemas de los municipios españoles, al tiempo que devalúa la autonomía local en nombre de la racionalización y la sostenibilidad.

\section{MÁS SOSTENIBILIDAD QUE RACIONALIZACIÓN: LOS OBJETIVOS DE LA REFORMA}

El mismo título de la Ley 27/2013, de 27 de diciembre, de racionalización y sostenibilidad de la Administración Local (en adelante, LRSAL) ${ }^{8}$ habla por sí solo de cuáles son los objetivos básicos de una norma que ha provocado una amplia contestación ${ }^{9}$. Su Preámbulo nos evidencia las contradicciones del legislador que, por una parte, dice «llegado el momento de someter a una revisión profunda el conjunto de disposiciones relativos al completo estatuto jurídico de la Administración local», pero que deja claro desde el principio que son realmente las exigencias derivadas del principio constitucional de estabilidad presupuestaria las que motivan la reforma. Un objetivo que parte además de una especie de «mito» consolidado en los últimos años consistente en hacer singularmente responsables a los entes locales del déficit del sector público español ${ }^{10}$.

debate riguroso sobre la «intermunicipalidad» en el Estado autonómico. ZAFRA VÍCTOR, M. «La provincia: lo importante no es el nombre, lo importante es la función», El Cronista del Estado social y Democrático de derecho, $\mathrm{n}^{\circ} 27,2012$, pp. 66-83.

7 ZAFRA VÍCTOR, M., «Autonomía local en el Estado autonómico», cit., p. 550.

$8 \mathrm{El}$ proceso de gestación de esta ley fue arduo y complejo. Fueron varios los borradores que se manejaron desde el gobierno y muchos los informes y valoraciones críticas que se fueron acumulando contra el mismo. Debemos recordar que el Consejo de Estado emitió un dictamen el 24 de mayo en el que subrayó varios aspectos de dudosa constitucionalidad del Anteproyecto. El Gobierno atendió algunas de estas indicaciones y ello dio lugar a un nuevo texto que apareció el 15 de julio de 2013. En esta nueva versión había desaparecido una de las aportaciones más controvertidas del Anteproyecto. Me refiero a la previsión de un coste estándar de los servicios a prestar por los municipios, lo cual los obligaba a una autoevaluación que, si resultaba negativa, provocaría como consecuencia que el servicio afectado pasara la Diputación Provincial. Una semana más tarde, el 22 de julio, apareció otro texto donde recuperaba, bajo otros términos, el coste efectivo y la prestación provincial de determinados servicios municipales en abierta oposición a las indicaciones del Consejo de Estado.

9 Véase en este sentido la Declaración emitida por la Comisión de Alcaldes de distintas fuerzas políticas contra la reforma en octubre de 2013 (http://estaticos.elmundo.es/documentos/2013/10/13/manifiestoalcaldes.pdf), en la que se concluía que el Proyecto vulneraba la autonomía local, invadía competencias autonómicas, penalizaba a las Administraciones que han hecho un mayor esfuerzo a favor de la contención del déficit público y no resolvía el problema de la financiación local. Como ejemplo de la contestación social y política véase el blog ¡No a la reforma local!: http://noalareformalocal.blogspot.com.es/. En los últimos meses se han publicado diversas monografías en las que se realiza un análisis crítico del texto. Entre ellas, cabe destacar las de MEDINA GUERRERO, M. La reforma del Régimen local, Tirant lo Blanch, Valencia, 2014; QUINTANA LÓPEZ, T. La reforma del régimen local, Tirant lo Blanch, Valencia, 2014; CEBRIÁN ABELLÁN, M. El régimen local tras la reforma de la Ley de Racionalización y Sostenibilidad. Bosch, Barcelona, 2014; DOMINGO ZABALLOS, M. J. Reforma del Régimen Local. La Ley de Racionalización y sostenibilidad de la Administración Local, Aranzadi, Cizur Menor, 2014.

10 «En el largo periodo 1995-2007, caracterizado por una gran expansión económica, el promedio de déficit del conjunto de las Administraciones Públicas fue del 1,35\% del PIB, una magnitud más que razo- 
La clave de la reforma es pues «la adecuada aplicación de los principios de estabilidad presupuestaria, sostenibilidad financiera o eficiencia en el uso de los servicios públicos locales», la cual se traduce en cuatro objetivos básicos: $1 .^{\circ}$ ) «clarificar las competencias municipales para evitar duplicidades con las competencias de otras Administraciones de forma que se haga efectivo el principio «una Administración una competencia»;.$^{\circ}$ ) «racionalizar la estructura organizativa de la Administración local de acuerdo con los principios de eficiencia, estabilidad y sostenibilidad financiera»; $3 .^{\circ}$ ) "garantizar un control financiero y presupuestario más riguroso» y $4 .^{\circ}$ ) «favorecer la iniciativa económica privada evitando intervenciones administrativas desproporcionadas» ${ }^{11}$. Lo que preocupa pues al legislador es la adecuación de los poderes locales a los principios rectores de la LO 2/2012, de 27 de abril, de Estabilidad Presupuestaria y Sostenibilidad Financiera (LOEPSF) ${ }^{12}$, la cual sirve de respaldo a la redefinición por parte del Estado de las competencias que deben ser desarrolladas por la Administración local. Para ello, y además de hacerlo en el artículo $135 \mathrm{CE}^{13}$, el legislador se apoya en los títulos competenciales de los arts. $149.1 .14 .^{\mathrm{a}}$ y $149.1 .18 .^{\mathrm{a} 14}$.

nable, muy por debajo del máximo del 3\% que establece como tope el Pacto de Estabilidad y Crecimiento. En el caso de las Corporaciones locales el saldo es prácticamente de equilibrio en ese periodo (...) En los primeros años de la crisis, entre 2008 y 2011, el panorama cambia por completo. El déficit público español supera el $8 \%$ del PIB, pero en las Entidades locales el déficit sigue siendo muy reducido en términos generales $(0,51 \%)$. De ahí es fácil colegir que la gran mayoría del déficit público ha sido generado en el nivel autonómico y, sobre manera, en el central». FERNÁNDEZ LLERA, R., «El endeudamiento de los concejos asturianos ante la nueva estabilidad presupuestaria», en RODRÍGUEZ-VIGIL RUBIO, J. L. y FERNÁNDEZ LLERA, R. (coord..), Crisis de los Ayuntamientos, crisis de la democracia, cit. , p. 189

$11 \mathrm{El}$ análisis crítico que aquí merecen algunos aspectos de esta reforma no impide el reconocimiento de las disfunciones que aquejaban desde el punto de vista competencial y financiero a los entes locales. Es decir, comparto la inviabilidad del modelo anteriormente vigente, subrayada por la crisis económica, y la necesidad de llegar a «una especie de acoplamiento de la vertiente competencial a la financiera, de manera estricta, huyendo de una especie de regla práctica que ha regido en el derecho local español durante décadas, consistente en que las entidades locales podía asumir <espontáneamente> competencias y actividades porque eso redundaba en el bienestar de los vecinos». DÍAZ LEMA, J. M., «El Anteproyecto de Ley de Racionalización y Sostenibilidad de la Administración Local: ¿cambio de rumbo en la Administración local española?», Anuario del Gobierno local, 2012, p. 56. Cuestión distinta es como se enfoca dicha cuestión en la LRSAL y la valoración de cómo afecta la misma a principios como el de autonomía local y democrático, así como al reparto competencial entre el Estado y las Comunidades Autónomas.

12 Esta ley ha sido calificada como «la pieza fundamental del bloque de constitucionalidad financiera y como una norma que cumple una determinada < función constitucional >». GARCÍA ROCA, J. MARTÍNEZ LAGO, M.A., Estabilidad presupuestaria y consagración del freno constitucional al endeudamiento, Civitas, Cizur Menor, 2013, p. 90.

13 Sobre la «constitucionalización» de la estabilidad presupuestaria véanse EMBID IRUJO, A., La constitucionalización de la crisis económica, Iustel, Madrid, 2012; el número monográfico de la revista Teoría y Realidad Constitucional — $\mathrm{n}^{\circ} 29,1^{\circ}$ semestre 2012 - dedicado a «La reforma constitucional»; LÓPEZ GARRIDO, D (ed.) y MARTÍNEZ ALARCÓN, L. (coord..), Reforma constitucional y estabilidad presupuestaria. C.E.P.C., Madrid, 2013, y CARRASCO DURÁN, M. «Estabilidad presupuestaria y Comunidades Autónomas», Revista d'Estudis Federals i Autonòmics, no 18 , 2013, pp. 169-216.

14 La invocación del artículo 149.1.13 que realizaba el Anteproyecto de LRSAL como fuente de competencia del Estado fue eliminada después de que el Consejo de Estado advirtiera en su Dictamen que era incorrecta e innecesaria, «al existir otros títulos más específicos que sí ofrecen al proyecto la cobertura constitucional necesaria para su aprobación por parte del Estado». 
Con respecto a su conexión con la LOEPSF, estoy de acuerdo con las críticas realizadas por Francisco Velasco cuando señala que: «la LRSAL no es una concreción o desarrollo de la LOEPSF sino una ley bien diferenciada. La Ley Orgánica 2/2012 establece un sistema de control financiero sobre los resultados globales de cada organización pública territorial (Comunidades Autónomas o entidades locales). Esto es: la LOEPSF establece principios finalistas y reglas de resultado (de déficit, endeudamiento y gasto) que han de cumplir las organizaciones públicas territoriales. En este sentido, la LOEPSF no impone a las organizaciones territoriales opciones concretas sobre cómo ejercer sus competencias sino qué objetivos y qué resultados deben cumplirse en el ejercicio de esas competencias (...) Hay, por tanto, espacio para la «opción política». Sin embargo, la LRSAL no se limita a establecer objetivos y reglas de resultado, más bien pretende dirigir el ejercicio de cada concreta competencia municipal (...)» ${ }^{15}$.

Esa fundamentación es la que legitima la potenciación de las Diputaciones Provinciales, las medidas de fomento de la fusión de municipios, la revisión de las entidades instrumentales que conforman el sector público local, el nuevo sentido que se le da a la coordinación de las entidades locales, el refuerzo del papel de la función interventora en ellas o la asunción por parte de las Comunidades Autónomas de las competencias relativas a la salud y servicios sociales. Incluso la creación de entes territoriales inferiores al municipio se condiciona al hecho de que resulte «una opción más eficiente para la administración desconcentrada de núcleos de población separados, de acuerdo con los principios previstos en la Ley Orgánica 2/2012, de 27 de abril, de Estabilidad Presupuestaria y Sostenibilidad Financiera» (nuevo art. 24 bis que sustituye al antiguo art. 45 que queda sin contenido) ${ }^{16}$.

Todo este conjunto de medidas evidencia que más que ante una ley de «racionalización» estamos ante una ley de «sostenibilidad» ${ }^{17}$, la cual es definida por

15 VELASCO CABALlERO, F. «Nuevo régimen de competencias municipales en el Anteproyecto de Racionalización y Sostenibilidad de la Administración Local», Anuario de Derecho Municipal, 2012, p. 26.

16 Con respecto a las existentes en el momento de entrada en vigor de la LRSAL, la DA $4^{a}$ prevé que mantendrán su personalidad jurídica y su condición de Entidad local, si bien con fecha de 31 de diciembre de 2014 deberán presentar sus cuentas ante los organismos correspondientes del Estado y de la Comunidad Autónoma respectiva para no incurrir en causa de disolución. La no presentación de las mismas será causa de disolución, que será acordada por Decreto del órgano de gobierno de la Comunidad autónoma respectiva. En este caso, «la eficiencia prima de nuevo sobre la potestad genérica de autoorganización de la Administración local. Pero el sentido de la exigencia es lógico: impedir la creación de infraestructuras administrativas, aún cercanas al ciudadanos y a los problemas del mismo, innecesarias, ineficientes o inadecuadas». MELLADO RUIZ, L. «Notas críticas sobre el Anteproyecto de ley para la racionalización y sostenibilidad de la Administración local: entre la reforma y la intervención», Revista CEMCI, no 17, octubre-diciembre 2912, p. 13. Estas previsiones en relación a las entidades inframunicipales suponen de nuevo una clara lesión de las competencias autonómicas. Como bien puso de manifiesto el Consejo de Estado en su Dictamen sobre el Anteproyecto, recordando la STC 214/1989, «se trata de unas Entidades con un fuerte grado de <interiorización> autonómica por lo que, en la determinación de sus niveles competenciales, el Estado no puede sino quedar al margen. Corresponde, pues, en exclusiva a las Comunidades Autónomas determinar y fijar las competencias de las Entidades locales que procedan a crear en sus respectivos ámbitos territoriales».

17 «La clave para entender su mensaje último (al margen de los detalles) es que pone el punto de mira sobre aquellas entidades locales y entes instrumentales que tienen (o puedan tener en el futuro) una situa- 
el art. 4.2 LOEPSF como «la capacidad para financiar compromisos de gasto presentes y futuros dentro de los límites de déficit, deuda pública y morosidad de deuda comercial conforme a lo establecido en esta Ley, la normativa sobre morosidad y en la normativa europea.» En este sentido, cabe destacar como el nuevo art. 116 ter LBRL obliga a las entidades locales a calcular antes del 1 de noviembre de cada año el coste efectivo de los servicios que prestan, partiendo de los datos contenidos en la liquidación del presupuesto general y, en su caso, de las cuentas anuales aprobadas por las entidades vinculadas o dependientes, correspondiente al ejercicio inmediato anterior ${ }^{18}$.

De esta manera, queda devaluada la la garantía constitucional de la autonomía local. Así se deja muy claro en la nueva redacción que se da al apartado 1 del art. 2 LBRL, donde si bien se reconoce el derecho de los entes locales a «intervenir en cuantos asuntos afecten directamente al círculo de sus intereses», se añade el inciso final que siempre «de conformidad con los principios de descentralización, proximidad, eficacia y eficiencia, y con estricta sujeción a la normativa de estabilidad presupuestaria y sostenibilidad financiera». Del artículo desaparece el criterio de «máxima proximidad de la gestión administrativa a los ciudadanos», como consecuencia lógica de los principios ahora dominantes: será la Administración más eficaz la que intervendrá en los asuntos que interesen a los vecinos, no la que sea más próxima a ellos. De esta forma, cobra vigor la limitación impuesta por el art. 4.3 CEAL al principio de subsidiariedad — «El ejercicio de las competencias públicas debe, de modo general, incumbir preferentemente a las autoridades más cercanas a los ciudadanos. La atribución de una competencia a otra autoridad debe tener en cuenta la amplitud o la naturaleza de la tarea o las necesidades de eficacia o economía» ${ }^{19}$ — y se enmienda la misma definición que de autonomía local ofrece dicho tratado — «el derecho y la capacidad efectiva de las entidades locales de ordenar y gestionar una parte importante de los

ción económico-financiera delicada (planes de ajuste, planes económico-financieros o de saneamiento, incumplimiento plazos de morosidad, etc.). Aquellos ayuntamientos que tengan o que caigan en una situación financieramente compleja lo pueden pasar mal, muy mal. Y no será fácil que pretendan sortear (con los «juegos de manos tradicionales») una situación como la descrita. Los municipios que tengan sostenibilidad financiera podrán mantener la actual cartera de servicios, el resto no. Aun así se prevén cambios radicales en algunos ámbitos sectoriales.» JIMÉNEZ ASENSIO, R., http://noalareformalocal.blogspot.com.es/ (consultada: 24/01/2013).

18 «El concepto de coste efectivo es equívoco y de imposible aplicación en la práctica. Es difícil creer que el Ministerio o las Diputaciones van a ser capaces de calcular el coste de prestación de estos servicios para más de 8000 municipios, teniendo en cuenta la completa inexistencia de información sobre costes y sobre resultados de provisión de estos servicios. Nótese que para este propósito no bastaría calcular un determinado nivel de gasto per cápita. El coste de prestación depende en la práctica de la tecnología de prestación utilizada, que es distinta en función de las características geográficas (e.g, dispersión, núcleos, orografía) y socioeconómicas (e.g., población estacional, actividad comercial e industrial) y del nivel de calidad demandado por la población.» BOSCH, N. SOLÉ-OLLÉ, A., «Reforma de la Administración Local», Informe sobre federalismo fiscal y finanzas públicas, Institut d’Economia de Barcelona, 2013, pp. 6-7.

19 Sobre las dudas que plantea la eficacia del principio de subsidiariedad en cuanto límite para el desplazamiento de competencias a un nivel superior de gobierno, véase el comentario de NARANJO DE LA CRUZ sobre el art. 90 del Estatuto Andaluz. CRUZ VILLALÓN, F. y MEDINA GUERRERO, M. Comentarios Estatuto de autonomía para Andalucía II, Parlamento de Andalucía, Sevilla, 2012, pp. 1455-1457. 
asuntos públicos en el marco de la Ley, baso su propia responsabilidad y en beneficio de sus babitantes» (art. 3) - ${ }^{20}$, así como el mandato de que las competencias atribuidas a los entes locales sean plenas y completas (art. 4.4). Además de por supuesto dejar reducido a mero señuelo formal el principio de subsidiariedad ${ }^{21}$.

Esta a mi parecer evidente lesión de la autonomía local parece ser «detectada» por el Consejo de Estado en su Dictamen sobre el Anteproyecto, aunque no llegue a expresarlo con contundencia. En una especie de malabarismo dialéctico, el Consejo de Estado afirma que «el mero hecho de que el haz de competencias que hasta ahora tenían reconocidas se vea reducido como consecuencia de la reforma proyectada no determina per se una afectación de la autonomía local de tal intensidad que pueda implicar una vulneración de la garantía institucional», si bien a continuación puntualiza que «tal conclusión no ha de impedir que el juego conjunto de los distintos preceptos que definen el nuevo modelo... da lugar a una considerable constricción de la autonomía de los Municipios...» 22 .

\section{LA REORDENACIÓN DE LAS COMPETENCIAS MUNICIPALES}

Tal y como se expresa en el Preámbulo, la Ley pretende clarificar las competencias municipales para evitar duplicidades y avanzar en el principio «una Administración una competencia». Un objetivo frente al que tal vez lo primero que habría que cuestionarse es si eso es totalmente posible en un modelo de descentralización territorial tan complejo como el nuestro. Es decir, quizás sería más sensato asumir la inevitable intersección de competencias y, en consecuencia, profundizar en los

20 Es interesante resaltar como la CEAL ha sido incorporada expresamente como criterio interpretativo en varios Estatutos de autonomía como el andaluz (art. 89.2) o el valenciano (art. 46.2). Como ha señalado VELASCO, «esta 'estatutorizacion' de una norma internacional puede resultar útil para dotar de una eficacia cuasiconstitucional a la CEAL. Esto es, para que la Carta Europea sirva de canon (mediato) de constitucionalidad ante las leyes autonómicas». «El estado de la autonomía local en 2007», Anuario de Derecho Municipal 2007, pp. 26-27. Debemos tener en cuenta que «la CEAL cierra los espacios abiertos en la Constitución y obliga a interpretar las disposiciones constitucionales de principios desde los criterios hermenéuticos que ella misma enuncia. Esa eficacia informadora se produce praeter y secundum Constitutionem: bien en defecto de previsiones constitucionales expresa bien de forma complementaria de las mismas». GARCÍA ROCA, J., «Un bloque constitucional local conforme al principio de subsidiariedad (desarrollo constitucional pendiente)», Revista de Estudios de la Administración Local y Autonómica, núms. 294-295, 2004, p. 35.

21 De esta manera, se pone en entredicho «el entendimiento de la autonomía local como una potestad universal de actuación pública preferente, políticamente responsable y constitucionalmente garantizada», la cual «supondría la inconstitucionalidad de todo intento legal por desapoderar a los entes locales para llevar a cabo todas aquellas iniciativas públicas o servicios que voluntariamente hubiesen decidido acometer, alegando carencia de título legal habilitante o invasión de competencias ajenas». CAAMAÑO DOMÍNGUEZ, F. La autonomía de los entes locales en positivo, Fundación Democracia y Gobierno Local, Madrid, 2003, p. 181.

22 En este sentido, no deja de sorprender que en el mismo Dictamen el Consejo de Estado no ponga ninguna objeción a que el Estado lleve a cabo una reducción del ámbito competencial de los Municipios, incluso en el caso de que eso afecte a lo definido por las Comunidades Autónomas. Sostiene el Consejo de Estado que el legislador estatal puede «efectuar una redefinición del ámbito competencial municipal, por más que ello obligue al legislador autonómico a introducir en su ordenamiento los ajustes necesarios». 
mecanismos de colaboración y coordinación ${ }^{23}$. En todo caso, ello obligaría a situar esta problemática «municipal» en el contexto de nuestro modelo autonómico y, por tanto, difícilmente quedaría resuelta de manera satisfactoria sin tener presentes los problemas que desde el punto de vista competencial y organizativo aquejan a los otros dos niveles territoriales.

Para lograr esa «racionalización» se reduce el ámbito de actuación municipal y se lleva a cabo una especie de «jerarquización» de las competencias y actividades locales: «Las competencias legales o propias predominan sobre las impropias o discrecionales, y dentro de las legales los servicios mínimos del artículo 26 adquieren un evidente protagonismo» ${ }^{24}$. Esta reordenación, como bien apuntara Francisco Velasco cuando el texto era sólo un Anteproyecto, parte de una premisa errónea que no es otra que entender que es el Estado el que fija las competencias municipales ${ }^{25}$.

La LRSAL lleva a cabo una reordenación de todo el sistema de competencias locales, a partir del nuevo art. 7 LBRL en el que distingue entre propias y atribuidas por delegación. Con respecto a esta última, pasa también a estar regida por los objetivos de «mejorar la eficiencia de la gestión pública, contribuir a eliminar duplicidades administrativas y ser acorde con la legislación de estabilidad presupuestaria y sostenibilidad financiera» (art. 27.1). Es decir, la delegación deja de ser una técnica de ampliación del poder local y se convierte en «un instrumento de reducción de costes en la gestión de competencias autonómicas y locales» ${ }^{26}$. Así el apartado $3^{\circ}$ del art. 27 deja claros objetivos de «evitar duplicidades administrativas, mejorar la transparencia de los servicios públicos y el servicio a la ciudadanía y, en general, contribuir a los procesos de racionalización administrativa, generando un aborro neto de recursos...»

Desaparece, en lógica sintonía además con el espíritu que domina la LRSAL, la referencia al objetivo de alcanzar una mayor participación ciudadana que preveía el anterior art. 27.1. Es evidente que lo que priman también en ese caso son los principios que responde a una lógica de mera eficiencia económica y en este sentido hay que entender todas las cautelas y requisitos que se establecen en el nuevo y extensísimo artículo 27, tales como la exigencia de una memoria económica en la que se justifiquen los principios arriba señalados o el acompañamiento de la correspondiente financiación (art. 27. 6). Además el legislador establece un listado de competencias que el Estado o las Comunidades Autónomas podrán delegar, «con el objeto de evitar

23 FONT I LLOVET, T. GALÁN GALÁN, A. «Racionalización y sostenibilidad de la Administración local: ¿es esta la reforma?», Anuario de Gobierno Local 2012, pp. 14-15.

24 DÍAZ LEMA, José Manuel. «El Anteproyecto de Ley de Racionalización y Sostenibilidad...», cit., p. 56.

25 «El Estado sólo puede atribuir competencias concretas a los municipios en aquellas materias que le son propias (como tráfico), pero no en las que son de titularidad autonómica. Esto era verdad en 1985 y es más verdad en 2012, después de que una buena parte de los Estatutos de Autonomía reformados entre 2006 y 2007 — como los de Andalucía, Cataluña y Aragón— hayan atribuido competencia exclusiva a la respectiva Comunidad Autónoma sobre «competencias» municipales o locales». VELASCO CABALLERO, F., «Reforma del régimen local: la nueva cultura política de la «intervención»» (artículo publicado en la página web del Instituto de Derecho Local: www.idluam.org, consultada 6/02/2014).

26 VELASCO CABALLERO, F. «Nuevo régimen de competencias municipales...»,cit., p. 44. 
duplicidades administrativas, mejorar la transparencia de los servicios públicos y el servicio a la ciudadanía y, en general, contribuir a los procesos de racionalización administrativa, generando un ahorro neto de recursos» (art. 27.3) ${ }^{27}$.

A su vez, la Ley reduce el margen de maniobra de los gobiernos locales en relación a las denominadas competencias impropias. Una denominación que el legislador, siguiendo la advertencia del Consejo de Estado, eliminó en el texto definitivo en el que se habla de «competencias distintas de las propias y de la atribuidas por delegación» (art. 7.4). Estas sólo podrán ser ejercidas por las Entidades Locales «cuando no se ponga en riesgo la sostenibilidad financiera del conjunto de la Hacienda municipal, de acuerdo con los requerimientos de la legislación de estabilidad presupuestaria y sostenibilidad financiera y no se incurra en un supuesto de ejecución simultánea del mismo servicio público con otra Administración pública» (art. 7.4 $)^{28}$. En todo caso se exige el informe previo y vinculante de la Administración competente por razón de la materia, «en el que se señale la inexistencia de duplicidades, y de la Administración que tenga atribuida la tutela financiera sobre la sostenibilidad financiera de las nuevas competencias».

La restricción del ámbito de actuación municipal queda patente también en la nueva redacción del art. 25.1 LBRL ${ }^{29}$ : «el Municipio, para la gestión de sus intereses y en el ámbito de sus competencias, puede promover actividades (antes decía «toda clase de actividades») y prestar los servicios públicos (antes «cuantos servicios públicos») que contribuyan a satisfacer las necesidades y aspiraciones de

27 Se ha introducido un nuevo art. 57 bis en el que se dispone, bajo el título de «Garantía de pago en el ejercicio de competencias delegadas», que «si las Comunidades Autónomas delegan competencias o suscriben convenios de colaboración con las Entidades locales que impliquen obligaciones financieras o compromisos de pago a cargo de las Comunidades Autónomas, será necesario que éstas incluyan una cláusula de garantía del cumplimiento de estos compromisos consistente en la autorización a la Administración General del Estado a aplicar retenciones en las transferencias que les correspondan por aplicación de su sistema de financiación». Llama la atención una previsión como ésta, y no solo porque supone la regulación de una materia que está sometida a la reserva de ley orgánica cual es la financiación de las CCAA (art. 157.3 CE), sino también por lo que de nuevo supone de intromisión en la autonomía financiera de aquéllas. Como bien ha señalado $\mathrm{M}$. MEDINA, «en los Estados federales de nuestro entorno — como Alemania_-, la capacidad de operar en las transferencias financieras de las que son titulares los entes subcentrales, reteniendo o suspendiendo su efectivo traspaso, se concibe como una forma muy severa de intromisión en su autonomía presupuestaria, hasta el punto de entenderse sólo constitucionalmente posible en el caso extremo de que se ponga en marcha la institución de la coerción federal». «Anteproyecto de Ley de racionalización y sostenibilidad de la Administración local», Reforma de la Ley de Régimen Local, Centro de Estudios Andaluces, Sevilla, 2013, p. 39.

28 El texto final recogió en este punto las sugerencias realizadas por el Consejo de Estado, en el sentido de evitar términos vagos e imprecisos — así se sustituye «la inexistencia de duplicidades» por «no se incurra en un supuesto de ejecución simultánea»-, así como en cuanto a la referencia a la sostenibilidad financiera del conjunto de la Hacienda Local.

29 Hay que tener en cuenta que la LBRL estaba construida «sobre una arquitectura difusa de las competencias y actividades locales, con el objetivo de cimentar una Administración local con una fuerte capacidad de iniciativa, en abierto contraste con la Administración local preconstitucional; la consecuencia natural de esto es lo que podríamos denominar principio de igual trato de las distintas competencias y actividades locales, sin un criterio claro de preferencia o de jerarquía entre unas y otras». DÍAZ LEMA, J.M, «El Anteproyecto de Ley de Racionalización y Sostenibilidad de la Administración Local: ¿Cambio de rumbo en la Administración Local española?», cit., pp. 53-54. 
la comunidad vecinal en los términos previstos en este artículo». La LRSAL reduce las competencias propias que pueden ejercer los municipios, las cuales serán determinadas por Ley y siempre con una previa evaluación sobre la «conveniencia de la implantación de servicios locales conforme a los principios de descentralización, eficiencia, estabilidad y sostenibilidad financiera» (art. 25.3). Es decir, a la «legitimidad democrática» se añade ahora una nueva «legitimidad económica» ${ }^{30}$. Se establecen además una serie de exigencias dirigidas a garantizar el cumplimiento de dichos principios, las cuales suponen o pueden suponer de hecho una considerable restricción del ámbito de autonomía municipal (art. 25.4) ${ }^{31}$.

Este nuevo régimen produce una «degradación de aquellas competencias que, no estando en el art. 25.2 LBRL, son atribuidas por leyes sectoriales. Es claro que una reforma de la LBRL puede alterar el régimen competencial vigente: Lo que no es tan claro es que la amplia competencia estatal para garantizar la autonomía funcional de los municipios ampare también, con la misma amplitud, la degradación de competencias municipales atribuidas por las Comunidades Autónomas (o, en sus materias sectoriales, también por el Estado) más allá del mínimo de «interés local» identificado en el art. 25.2 LBRL» ${ }^{32}$.

En cuanto al listado de materias que se incluyen en el nuevo art. 25.2, y junto a la reordenación de algunos contenidos y actualización de otros, lo más llamativo es la supresión de la «participación en la gestión de la atención primaria de la salud» así como de «la prestación de los servicios sociales y promoción y reinserción social». Esta supresión ha merecido una amplia contestación no sólo de muchas entidades locales sino también de colectivos sociales y vecinales que cuestionan que sin esas competencias los municipios puedan responder a las necesidades ciudadanas más inmediatas. Ello supone alejar a los entes locales de un modelo en el que las estructuras políticas y administrativas más cercanas al individuo jugaban un papel esencial en el mantenimiento de las condiciones de bienestar. Es decir, ello supone no solo reducir la autonomía local sino también el papel que los municipios deberían satisfacer en cuanto al cumplimiento de los objetivos propios de un Estado

30 MELLADO RUIZ, L. «Notas críticas sobre el proyecto de ley...», cit., p. 24.

31 En concreto, dichas exigencias son las siguientes: $1^{\circ}$ ) la Ley debe ir acompañada de una memoria económica que refleje el impacto sobre los recursos financieros de las Administraciones públicas afectadas y el cumplimiento de los citados principios; $2^{\circ}$ ) debe prever la dotación de los recursos necesarios para asegurar la suficiencia financiera de las Entidades locales sin que ello pueda conllevar, en ningún caso, un mayor gasto de las Administraciones Públicas; $3^{\circ}$ ) debe asimismo acompañarse de un informe del Ministerio de Hacienda y Administraciones Públicas en el que se acrediten los criterios antes señalados. Además, y de acuerdo con el principio de «una Administración una competencia», la Ley que atribuya la competencia deberá garantizar que no se produce la atribución simultánea de la misma a otra Administración Pública (art. 25.5). Ante esta última exigencia, deberíamos en todo caso hacernos la siguiente pregunta: «¿puede una ley sectorial «deslindar» de forma nítida las competencias locales que atribuye de las «competencias» — muy por encima de ella- estatales y autonómicas con vinculación o accesoriedad». MELLADO RUIZ, L. «Notas críticas sobre el anteproyecto de ley...», cit., p. 25.

32 VELASCO CABALLERO, F. «Nuevo régimen de competencias...», cit., p. 38. 
Social $^{33}$. Todo ello, además, en entredicho con las previsiones ya realizadas en ámbitos autonómicos como el andaluz, en el que LAULA, partiendo de las previsiones estatutarias, establece un determinado «modelo» de municipio que la LRSAL contradice ${ }^{34}$.

En consecuencia, queda en entredicho la misma atribución que el art. 25.1 realiza al municipio en el sentido de que «puede promover actividades y prestar los servicios públicos que contribuyan a satisfacer las necesidades y aspiraciones de la comunidad vecinal en los términos previstos en este artículo». En la misma línea hay que situar la supresión del art. 28 LBRL, es decir, la posibilidad de que los municipios puedan realizar «actividades complementarias de las propias de otras Administraciones públicas y, en particular, las relativas a la educación, la cultura, la promoción de la mujer, la vivienda, la sanidad y la promoción del medio ambiente» ${ }^{35}$. Aunque es cierto que el art. 28 LBRL ha podido dar lugar ac-

33 En este sentido resulta especialmente llamativo que el preceptivo Informe de impacto de género que en su día se añadió al Anteproyecto señalara que el mismo es «nulo». Una conclusión que obviamente desconoce los efectos que en la práctica puede tener por ejemplo que los municipios dejen de prestar determinados servicios sociales que tienen una clara incidencia en la protección de los derechos de las mujeres. De hecho, durante la tramitación del proyecto fueron varios los colectivos de mujeres que se movilizaron en contra de la reforma. Así se expresó por ejemplo en el Informe relativo al impacto en las políticas de igualdad del Anteproyecto LRSAL elaborado por el Consejo Andaluz de Participación de las mujeres. En dicho informe se indica como la nueva ley excluiría a la Administración local del ámbito de actuación de la LO 3/2007, para la igualdad efectiva de Mujeres y Hombres, dejando sin sentido su art. 21.2: «Las Entidades locales integrarán el derecho de igualdad en el ejercicio de sus competencias y colaborarán, a tal efecto, con el resto de las Administraciones públicas. En el mismo sentido, incidiría en las previsiones de la Ley 12/2007, para la Promoción de la Igualdad de Género en Andalucía. Por otra parte, se llamaba la atención sobre como la incidencia en la participación de las Corporaciones locales en el ámbito de aplicación de la LO 1/2004, de Medidas de Protección integral contra la violencia de género (art. 19), así como de la Ley andaluza 13/2007, de medidas de prevención y protección integral contra la violencia de género, en lo relativo a las competencias de los municipios respecto a las mujeres víctimas de violencia de género (art. 41)

34 Valga como ejemplo la regulación que el Título II LAULA hace de los servicios y la iniciativa económica local. Su capítulo I contiene una regulación detallada del régimen jurídico de los servicios locales de interés general, los cuales se definen como «Los que prestan o regulan, y garantizan, las entidades locales en el ámbito de sus competencias y bajo su responsabilidad, así como las actividades y prestaciones que realizan a favor de la ciudadanía orientadas a hacer efectivos los principios rectores de las políticas públicas contendías en el Estatuto de Autonomía de Andalucía». Por lo tanto, el legislador amplía los servicios que prestar los municipios en función de los objetivos que marca el art. 38 del Estatuto andaluz, el cual a su vez remite al capítulo II del Título I EAA — «Derechos y deberes»—y al art. 10 EAA, dedicado a los «Objetivos básicos de la Comunidad Autónoma». De esta manera, comprobamos como el legislador andaluz había optado por considerar a las entidades locales una pieza clave en la garantía de los derechos sociales consagrados en el Estatuto, algo que ahora niega el legislador básico estatal.

35 Con relación a esta supresión, no estoy totalmente de acuerdo con el juicio que realiza DÍEZ LEMA, el cual estima que «las actividades complementarias del artículo 28 podrían tener sentido en el marco de la Ley $7 / 1985$, lógicamente preocupada por el fortalecimiento de la iniciativa local, pero en el contexto de la reforma de 2012-13 dichas actividades complementarias son causa de distorsión, porque contribuyen a generar duplicidades administrativas, y son redundantes desde una perspectiva financiera». «El Anteproyecto de Ley de Racionalización y Sostenibilidad de la Administración Local...», cit., p. 58. Y no lo estoy porque en esa valoración no entran en juego principios como el de subsidiariedad, mayor cercanía a los intereses vecinales, inmediatez o participación democrática, lo cuales no deberían haberse obviado en el diseño de los entes locales que hace la nueva ley. 
tividades superpuestas o duplicadas respecto de las autonómicas y provinciales, más bien lo que dicho artículo procuró es «que los ayuntamientos cubrieran servicios y necesidades vecinales que no estaban debidamente cubiertos por las Comunidades Autónomas. Por lo demás, la experiencia jurisprudencial muestra que son raros los casos en los que los ayuntamientos han basado su actuación directamente en el art. 28 LBRL. Muchas actividades municipales que se consideran hoy duplicadas se amparan en títulos competenciales específicos: en lo que establecen las leyes autonómicas de vivienda, de urbanismo, de servicios sociales o de empleo. Por eso mismo, que nadie piense que con la supresión del art. 28 LBRL desaparecerán las actividades administrativas duplicadas. Si desaparecen será, más bien, porque los ayuntamientos no puedan financiarlas y porque las Comunidades Autónomas dejen de otorgar subvenciones condicionadas para tales actividades o servicios municipales. Pero cuando vuelva a ver recursos económicos disponibles, volverán a cubrir todas las demandas ciudadanas, sea al amparo de competencias sectoriales (interpretadas de forma extensa) o invocando de forma laxa - y previsiblemente incontestada, como hasta hoy - una competencia universal ex art. $137 \mathrm{CE}{ }^{36}$. Además, hay que tener en cuenta que las competencias «distintas de las propias y de las atribuidas por delegación» a que se refiere el art. 7.4 LBRL podrán dar cobertura las mismas actividades que hasta ahora encontraban acomodo en el art. $28 \mathrm{LBRL}^{37}$.

Por otra parte, no hay que olvidar que las Comunidades Autónomas pueden «elevar» en su territorio los estándares estatales de autonomía local. De hecho, varias de ellas, como la andaluza o la catalana, incluyen en su legislación de régimen local títulos competenciales generales o competencias complementarias similares a las del art. 28 LBRL. Debemos entender que estas normas no se verán afectadas por la derogación de dicho artículo. Esta solo supondrá «que no queda garantizada en toda España una competencia «complementaria» general de los ayuntamientos» ${ }^{38}$.

Todavía más discutible aún resulta que las Disposiciones Transitorias Primera, Segunda y Tercera de la Ley prevean la asunción por las Comunidades Autónomas de las competencias relativas a salud, servicios sociales y servicios de inspección sanitaria. Es de más que dudosa constitucionalidad que el legislador estatal realice esta atribución «obligatoria» y que incluso establezca plazos y condiciones para la asunción de esos ámbitos competenciales. De esta manera, «las bases estatales no fijan mínimos para que las Comunidades Autónomas desarrollan, amplían o precisan sino máximos que no pueden mejorar; no delimitan en negativo las competencias autonómicas sino que las definen en positivo» ${ }^{39}$. Una previsión que choca, por

36 VELASCO CABALLERO, F. «Reforma del régimen local...», cit., p. 2. Esta supresión fue censurada en las Alegaciones realizadas por la FEMP al Anteproyecto de LRSAL, en las que se invocó el art. 4.2 CEAL, según el cual «las Entidades locales tienen, dentro del ámbito de la Ley, libertad plena para ejercer su iniciativa en toda materia que no esté excluida de su competencia o atribuida a otra autoridad».

37 Velasco Caballero, F. «Nuevo régimen de competencias...», cit. P. 41.

38 VELASCO CABALLERO, F. «Nuevo régimen de competencias...», cit. P. 43.

39 ZAFRA VÍCTOR, M., «Esta reforma local empobrece la democracia», El País, 1 de agosto de 2013. En el mismo sentido, se pronuncian T. FONT I LLOVET - A. GALÁN GALÁN, los cuales subrayan como 
ejemplo, con las previsiones que realiza el Estatuto andaluz en su art. 92 al incluir entre las competencias propias de los municipios la gestión de los servicios sociales comunitarios o la cooperación con otras Administraciones públicas para la promoción, defensa y protección de la salud pública. Competencias que son especificadas con todo detalle en el art. 9 LAULA ${ }^{40}$.

Además resulta paradójico que en esas disposiciones se prevea que las Comunidades autónomas puedan en todo caso delegar dichas competencias en los entes locales de acuerdo con el art. 27 LBRL, de tal forma que podría plantearse la situación de que el Estado prive a los entes locales de dichas competencias, las atribuya a la Comunidad autónoma respectiva y ésta las delegue, volviendo por tanto al ámbito del que no debieron salir. Sin duda, un buen ejemplo de la más que deficiente técnica legislativa que domina el texto.

En el caso de las competencias relativas a educación, la Disposición adicional decimoquinta remite a las normas reguladoras del sistema de financiación de las CCAA y de las haciendas locales, las cuales fijarán los términos en los que aquéllas asumirán la titularidad de las competencias locales relativas a participar en la vigilancia del cumplimiento de la escolaridad obligatoria y cooperar con las Administraciones educativas correspondientes en la obtención de los solares necesarios para la construcción de nuevos centros docentes, así como la conservación, mantenimiento y vigilancia de los edificios de titularidad local destinados a centros educativos. Esta disposición resulta contradictoria con la aparición de dichas competencias entre las que la LRSAL considera como «propias» del municipio (art. 25.2.n ${ }^{41}$.

De esta manera, la LRSAL pone de manifiesto los evidentes problemas de articulación entre «una pluralidad de fuentes normativas de distinta naturaleza jurídica: constitucional, cuasiconstitucional o estatutaria, legislativa «básica» (Estado y Comunidad Autónoma) y legislativa sectorial (estatal y autonómica).» Si, como bien señalaba Gerardo Ruiz-Rico, «los criterios que rigen esa relación no son fáciles de delimitar de una manera exacta y absolutamente previsible en términos de

«se plantea una situación, inédita hasta la fecha, en la que el legislador estatal atribuye directamente a las Comunidades Autónomas las competencias que hoy en día tienen atribuidas los municipios — por leyes autonómicas, incluso con garantía en los estatutos - en las materias de educación, sanidad y servicios sociales. No parece, a primera vista, que estas traslaciones competenciales, en materias sectoriales de competencia autonómica, pueda hacerlas el legislador estatal en materia de régimen local, si no es en garantía de la autonomía local, que no es el caso». «Racionalización y sostenibilidad de la Administración local: ¿Es ésta la reforma?», cit., p. 20. En un sentido similar, F. VELASCO en «Nuevo régimen de competencias...», cit., p. 50 . En un sentido opuesto, sin embargo, se pronunció el Consejo de Estado, el cual de manera bastante discutible sostuvo que «el hecho de que ello interfiera con la regulación autonómica vigente no permite concluir que exista en este caso una vulneración de las competencias autonómicas».

40 A ello habría que sumar que «no está nada claro que las CCAA tengan los recursos necesarios y la voluntad de garantizar una provisión estándar de estos servicios en todo su territorio, por lo que en la práctica la transferencia literal de la competencia a la CA podría hacer que estos servicios dejasen de prestarse, con consecuencias muy negativas en el caso de municipios especialmente necesitados». BOSCH, N. SOLÉ-OLLÉ, A. «Reforma de la Administración Local», cit., p. 5.

41 La reforma ha suprimido la competencia que la LBRL reconocía sobre la participación de los municipios en «la programación de la enseñanza». 
seguridad jurídica», la LRSAL ha venido a introducir no solo mayor complejidad sino también muchas dudas en cuanto a su correcta inserción en un esquema de fuentes condicionado por la «estatutorización» del régimen local ${ }^{42}$. Estas más que discutibles previsiones de la LRSAL contradicen la línea doctrinal que comparto en cuanto a cual debiera ser la relación de la legislación básica estatal con los Estatutos de autonomía. Estoy de acuerdo con la doctrina que, ajustándose a varios enjuiciamientos del TC (sentencias 214/1989, 27/1987, 109/1988), estima que dicha legislación ocupa una posición infraordenada respecto al Estatuto de autonomía. Por lo tanto, una norma básica estatal será inaplicable cuando entre en conflicto con un Estatuto. Ahora bien, en aplicación del principio constitucional de autonomía local, «la aplicación del Estatuto puede considerarse condicionada a que su regulación no reduzca los "estándares básicos" de la autonomía local fijados por el Estado»"43.

Uno de los aspectos más discutibles de la Ley es la regulación que realiza de los servicios obligatorios ${ }^{44}$, sobre todo en lo que respecta a los municipios con población inferior a 20.000 habitantes. El procedimiento previsto en el art. 26.2 deja claramente sin contenido la autonomía de estos municipios desde el momento en que atribuye a la Diputación provincial o entidad equivalente la coordinación de la prestación de dichos servicios ${ }^{45}$. Para ello, y de conformidad con los Municipios afectados, propondrá al Ministerio de Hacienda y Administraciones Públicas la forma de prestación. Para reducir los costes efectivos de los servicios el mencionado Ministerio decidirá sobre la propuesta formulada que deberá contar además con el informe preceptivo de la Comunidad Autónoma si es la Administración que ejerce la tutela financiera. El municipio sólo podrá asumir la prestación y coordinación

42 RUIZ-RICO, G. «Título III. Organización territorial de la Comunidad Autónoma», en CRUZ VILLALÓN, P. MEDINA GUERRERO, L. (dir.), Comentarios Estatuto de Autonomía para Andalucía, II. cit., pp. 1426-1427.

43 VELASCO, F., «El estado de la autonomía local en 2007», cit. , p. 32. En un sentido similar, se pronuncia T. FONT I LLOVET, «Autonomía local y estatutos: crónica de un compromiso», Anuario de Gobierno Local, 2006, p. 27.

44 «La reducción parcial de los servicios obligatorios mínimos, tal y como resulta del nuevo art. 26 LBRL, no implica necesariamente que los ayuntamientos dejen de prestar tales servicios. Los servicios o actividades enumerados en el art. 26.1 LBRL son obligaciones «mínimas». Por eso, la simple supresión de la norma estatal no significa que desaparezca el servicio obligatorio y, menos aún, la competencia que le da sentido. Las leyes sectoriales del Estado y, sobre todo, las leyes municipales o sectoriales autonómicas pueden mantener como servicios públicos municipales obligatorios... actividades suprimidas del listado del art. 26.1 a) LBRL». Velasco Caballero, F. «Nuevo régimen de competencias...», cit. p. 39.

45 El texto definitivo eliminó de este artículo y de otros del Anteproyecto en los que también se usaba, siguiendo la recomendación del Consejo de Estado, la referencia al «coste estándar» de estos servicios, el cual sería fijado por Real Decreto del Gobierno. El Consejo de Estado estimó que «la remisión que en este punto realiza la norma legal a la norma reglamentaria es tan amplia y carente de parámetros legales que prácticamente puede considerarse como una habilitación en blanco al Gobierno», además de lo inadecuado que sería aplicarlo de manera única para todos los Municipios, dada la heterogeneidad de la realidad municipal española. Por otra parte, el Dictamen señaló que «exigir que cada servicio se preste sin rebasar un determinado umbral (coste estándar) y someterlo a una evaluación orientada a determinar que no hay alternativas menos costosas desde el punto de vista de economías de escala puede perturbar el sistema de atribución competencial e interferir en la autonomía municipal de tal modo que su efectividad quede precarizada como consecuencia de estar permanentemente sometida a cuestión, cuando no diluida o seriamente comprometida». 
de estos servicios si justifica ante la Diputación que puede prestarlos con un coste efectivo menor que el derivado de la forma de gestión propuesta por aquélla. Es decir, lo relevante no es que una entidad local con legitimidad democrática directa, dotada de autonomía política, preste determinados servicios a sus vecinos, sino que en todo caso pueda hacerlo con un menor coste y siempre bajo la tutela de otras Administraciones. En el caso además de las Diputaciones, bajo la tutela de una institución que carece de legitimidad democrática directa. Comprobamos pues como se reduce el ámbito de dirección política del municipio o, lo que es lo mismo, se reduce al mínimo la garantía constitucional de la autonomía local. Ante lo que no estaría de más recordar lo que tempranamente señalara el Tribunal Constitucional al excluir «los controles genéricos e indeterminados que sitúen a las entidades locales en una posición de subordinación o dependencia cuasi jerárquica de la administración del Estado u otras entidades territoriales (cursiva mía)»(STC 4/81).

Las dudas de constitucionalidad son más que evidentes en el caso de las Comunidades autónomas provinciales, ya que en este caso sería la propia Administración Autonómica la que pasaría a ejercer las competencias municipales. A ello habría que sumar que en la práctica se producirá una «severa erosión del sistema democrático, uno de cuyos pilares esenciales es la rendición de cuentas de los cargos políticos ante la sociedad. Y el principal control social se produce en el momento electoral, cuando los ciudadanos aprueban o desaprueban el modo en que han gestionado los asuntos públicos. No es precisa mucha perspicacia política para comprender que ... en aquellos municipios que hayan perdido el ejercicio de una parte apreciable de sus competencias las elecciones se convertirán en un mero ritual vacío de contenido» ${ }^{46}$.

\section{EL FORTALECIMIENTO DE LAS DIPUTACIONES PROVINCIALES}

Una de las apuestas más discutibles de la LRSAL es el fortalecimiento de la Diputaciones Provinciales, lo cual no deja también de resultar paradójico en el contexto de un debate que en los últimos años ha cuestionado precisamente el papel de estos entes, abogándose incluso en muchos casos por su desaparición ${ }^{47}$. La actual Ley, en lugar de mejorar su función tradicional de apoyar y colaborar con los municipios que no están en condiciones de prestar adecuadamente los servicios públicos, opta por una solución discutible desde el punto de vista constitucional y que choca incluso con lo previsto por algún legislador autonómico ${ }^{48}$. Así ocurre por ejemplo

46 MEDINA GUERRERO, M., «Anteproyecto de Ley de Racionalización y sostenibilidad de la Administración Local», cit., p. 37.

47 «Estamos ante una suerte de «redención de las provincias» orteguiana, objetivo hoy cumplido a nivel autonómico, con carácter general? ¿Cabe entroncar esto con las viejas propuestas de García de Enterría —años cincuenta- acerca de la provincialización de los servicios públicos municipales?». FONT I LLOVET, T. y GALÁN GALÁN, A., op. cit., p. 15.

48 «Por imperativo constitucional (artículo 141) la diputación tiene atribuida las facultades de gobierno y administración de la provincia. A tal efecto la provincia dispone de competencias que garanticen la presta- 
con lo previsto por la LAULA, en la que queda muy claro el papel de asistencia técnica, económica y material a desempeñar por las provincias (art. 11). En este caso nos encontraríamos con el desplazamiento de «una Ley autonómica cuya adecuación a la Constitución y al Estatuto nunca se puso en cuestión» ${ }^{49}$.

En relación a este fortalecimiento habría que recordar lo dicho por el Tribunal Constitucional en la STC 103/2013, de 25 de abril, sobre la impugnación del artículo 36.1.c LBRL, tras la redacción dada por la Ley 57/2003, que atribuía las Diputaciones Provinciales la prestación de servicios de carácter supramunicipal. El Parlamento de Cataluña entendía que dicha atribución suponía no solo una reducción de la autonomía de los entes locales por parte de una institución pensada para darles apoyo sino que también vulneraba la competencia del legislador autonómico. El TC mantuvo sin embargo que dicha atribución obedecía al reforzamiento del papel de las entidades provinciales que perseguía la Ley 57/2003 y que el precepto impugnado no podía considerarse contrario a la garantía constitucional de la autonomía provincial, "pues ésta no sólo no se ha eliminado, sino que se ha ampliado con la atribución de una nueva competencia; pero tampoco, tal y como aparece legalmente formulada, vulnera el núcleo esencial de la autonomía del resto de los entes locales, cuyas competencias no se han visto modificadas». No creo, sin embargo, que la nueva dimensión que el legislador básico estatal ha atribuido a las Diputaciones deba merecer la misma consideración jurídico-constitucional que la que se planteó en la sentencia comentada, ya que sí que parece evidente la vulneración de la autonomía local y, sobre todo, con más rotundidad aún, la colisión con el ámbito competencial autonómico. La conclusión a la que se llega con la nueva regulación es perversamente paradójica: «Si la provincia asiste bien a los Ayuntamientos para que su baja capacidad de gestión no los prive de competencias, difícilmente se explica que, por la misma razón, los suplante; es decir, si los suplanta es porque no los asistió adecuadamente». Es decir, la LRSAL «deshace la configuración constitucional de la provincia como agrupación de municipios y la realza como división territorial para el cumplimiento de los fines del Estado, en este caso, el recorte presupuestario, eufemísticamente justificado bajo las expresiones de racionalización y sostenibilidad» ${ }^{50}$.

Comparto en este sentido las observaciones que al respecto hizo el Consejo de Estado en su Dictamen sobre el Anteproyecto de LRSAL: «Disponer la supresión

ción integral de servicios para que la vecindad administrativa no provoque discriminación en el acceso a ellos; el sentido de la provincia, pues, no está en suplantar a los municipios sino en asistirlos para evitar que la baja capacidad de gestión les prive de la titularidad de sus competencias y evite la efectividad del principio de subsidiariedad». ZAFRA VÍCTOR, M. «Análisis y valoración del Anteproyecto de ley para la racionalización y sostenibilidad de la Administración Local», Reforma de la Ley de Régimen Local, cit., p. 30.

49 MEDINA GUERRERO, M. , «Anteproyecto de Ley de Racionalización y sostenibilidad de la Administración Local», cit., p. 38. Sobre el papel de las provincias en la Comunidad autónoma andaluza véase SALAZAR BENÍTEZ, O. «Comentario artículo 96. La Provincia», en CRUZ VILLALÓN, P. MEDINA GUERRERO, M. (dir.), Comentarios Estatuto de Autonomía para Andalucía, cit., p. 1563-1566. Sobre como deberían ser las relaciones entre la provincia y los municipios véase ZAFRA VÍCTOR, M. «La provincia...», cit.

50 ZAFRA VÍCTOR, M., «Esta reforma local empobrece la democracia», El País, 1 agosto de 2013. 
de contenidos fundamentales de la autonomía local con base en el incumplimiento de un parámetro económico — y único- configurado como elemento del que depende la continuidad de la prestación de servicios por parte del Municipio puede afectar negativamente al núcleo esencial de la garantía institucional antes explicadas, sin que pueda obviarse, además, que la traslación de competencias actúa a favor de las Diputaciones Provinciales, que son entidades representativas de segundo grado no sujetas, por tanto, en cuanto a composición, mecanismos de elección directa (con la notable excepción de las Diputaciones del País Vasco). Ello implica, entre otras cosas, que no quepa exigir a estas entidades responsabilidad política en caso de que la gestión desarrollada no se adecue a las disposiciones aplicables o, simplemente, no se considere adecuada por los ciudadanos, lo que en última instancia puede llegar a desvirtuar el principio democrático... ${ }^{51}$.

En concreto, el nuevo art. 26.2 LBRL prevé que en los municipios con población inferior a 20.000 habitantes será la Diputación provincial o entidad equivalente la que coordinará la prestación de los siguientes servicios: a) Recogida y tratamiento de residuos; b) Abastecimiento de agua potable a domicilio y evacuación y tratamiento de aguas residuales; c) Limpieza viaria; d) Acceso a los núcleos de población; e) Pavimentación de vías urbanas; f) Alumbrado público. Para llevar a cabo esa coordinación la Diputación propondrá, con la conformidad de los municipios afectados, al Ministerio de Hacienda y Administraciones Públicas la forma de prestación, consistente en la prestación directa por la Diputación o la implantación de fórmulas de gestión compartida a través de consorcios, mancomunidades u otras fórmulas. Para reducir los costes, el Ministerio de Hacienda decidirá sobre la propuesta formulada que deberá contar con el informe preceptivo de la Comunidad Autónoma si es la Administración que ejerce la tutela financiera.

Sólo si el municipio justifica ante la Diputación que puede prestar estos servicios con un coste efectivo menor que el derivado de la forma de gestión propuesta por la Diputación, podrá asumir la prestación y coordinación de los mismos «si la Diputación lo considere acreditado». El criterio, por tanto, para garantizar en última instancia la autonomía municipal es el coste de los servicios y no otros como la calidad de su prestación, la mayor inmediatez y acomodo a las necesidades del vecindario, la mayor participación ciudadana o el desarrollo de un determinado programa político. Es decir, los principios de autonomía y democrático quedan subordinados a las exigencias derivadas de la estabilidad presupuestaria y la sostenibilidad. De esta manera no solo queda en entredicho la garantía institucional de la autonomía local como límite del legislador sino también la misma definición que

51 El gobierno hizo caso omiso de las recomendaciones del Consejo de Estado en el sentido de recoger otras fórmulas alternativas o complementarias más respetuosas con la autonomía municipal, tales como la asunción de competencias por parte de una mancomunidad o cualquier otra forma de asociación voluntaria de municipios. 
de la misma da la CEAL como derecho de la entidad local a ordenar y gestionar una parte importante de los asuntos públicos bajo su propia responsabilidad ${ }^{52}$.

Y todo ello a favor de una institución que, no lo olvidemos, carece de legitimidad democrática directa y se ha convertido en los últimos años en objeto de abundantes críticas que denuncian su «colonización» por los «aparatos partidistas $»^{53}$. Además, la reforma dará lugar a una suerte de «asimetría institucional» en función de las relaciones que las Diputaciones tendrán con los municipios, lo cual debería llevar a plantearnos que también serían necesarios distintos esquemas organizativos, de forma que finalmente hubiera «unos municipios «con más» diputación y otros «con menos» o, incluso, «libres de diputación» ${ }^{54}$. Sin olvidarnos de si realmente las Diputaciones tienen capacidad suficiente para la prestación de los servicios que se le atribuyen, al tiempo que nos tendríamos que cuestionar qué ocurriría con los Ayuntamientos que dejan de prestarlos: «Si se busca la racionalización organizativa y el reequilibrio institucional, ¿tiene sentido privar de competencia a los Ayuntamientos y dejarlos con su misma estructura y composición?, es decir, y contraviniendo un principio nuclear de nuestro derecho administrativo de la organización, despojar de competencias a determinados órganos municipales, pero manteniéndolos y, por tanto, costeándolos entre todos» ${ }^{55}$.

\section{OTRAS MEDIDAS DE SUPUESTA RACIONALIZACIÓN}

Entre las medidas de racionalización de la Administración local que introduce la LRSAL cabe destacar las siguientes:

1. ${ }^{a}$ La revisión del conjunto de entidades instrumentales que conforman el sector público local, una racionalización de sus órganos de gobierno y una ordena-

52 «Y esta situación, ¿podría considerarse, además, que rompe con la imagen social que se tiene al menos desde 1985, sobre las responsabilidades políticas del municipio para decidir autónomamente sobre los servicios mínimos obligatorios, haciéndolos irreconocibles como entes dotados de autogobierno? Sería la primera vez que la «garantía institucional» podría ser una verdadera garantía». FONT I LLOVER, T. «Hacia la reforma del régimen local: racionalización y sostenibilidad», Informe Comunidades Autónomas 2012, Instituto de Derecho Público, Barcelona, 2013, p. 218.

53 El fortalecimiento competencial de la provincia debería acompañarse de un simultáneo fortalecimiento institucional y organizativo, lo cual debería pasar por una reforma del sistema de elección del Pleno de la Diputación. FONT I LLOVET, T., GALÁN GALÁN, A. , op. cit., p. 16. En el mismo sentido, VELASCO, F. «Reforma del régimen local...», cit., p. 3. Con relación a este refuerzo del papel de las Diputaciones, habría que tener presentes las conclusiones a las que se llegó en el VIII Congreso de la Asociación Española de Derecho Administrativo dedicado a la Reforma de la planta del Gobierno Local, en las que se subrayó lo inadecuado de la organización, procedimientos, o medios personales y materiales con que cuentan las Diputaciones para la correcta prestación de servicios públicos de ámbito municipal. Además de todas las consecuencias que ello puede generar desde el punto de vista del régimen jurídico del personal, bienes y recursos municipales. FONT I LLOVET, T., GALÁN GALÁN, A., ibídem, p. 26.

54 FONT I LLOVET, T. y GALÁN GALÁN, A., op. cit., p. 17.

55 MELLADO RUIZ, L. «Notas críticas sobre el anteproyecto de ley para la racionalización...», cit., p. 10 . 
ción de las retribuciones del personal al servicio de las Corporaciones locales. En relación a este último aspecto, se introduce un nuevo art. 75 bis en el que se prevé que los Presupuestos Generales del Estado determinarán, anualmente, el límite máximo total que pueden percibir los miembros de las Corporaciones locales ${ }^{56}$. A ello habría que sumar la limitación en el número de cargos públicos de las Entidades locales con dedicación exclusiva (art. 75 ter), así como a las retribuciones en los contratos mercantiles y de alta dirección del sector público local y al número máximo de miembros de los órganos de gobierno (disposición adicional duodécima) ${ }^{57}$.

En este mismo sentido hay que destacar la previsión que realiza la nueva Disposición Adicional Decimosexta, según la cual «cuando el Pleno de la Corporación Local no alcanzara, en una primera votación, la mayoría necesaria para la adopción de acuerdos prevista en esta Ley, la Junta de Gobierno Local tendrá competencia para aprobar: a) El presupuesto del ejercicio inmediato siguiente, siempre que previamente exista un presupuesto prorrogado; b) Los planes económico-financieros, los planes de equilibrio y los planes de ajuste a los que se refiere la LO 2/2012, de 27 de abrir; c) Los planes de saneamiento de la Corporación Local o los planes de reducción de deudas; d) La entrada de la Corporación Local en los mecanismos extraordinarios de financiación vigentes a los que se refiere la LO 2/2012, de 27 de abril, y, en particular, el acceso a las medidas extraordinarias de apoyo a la liquidez previstas en el Real Decreto-Ley 8/2013, de 28 de junio, de medidas urgentes contra la morosidad de las administraciones públicas y de apoyo a Entidades Locales con problemas financieros». En estos casos, la Junta de Gobierno local sólo está obligada a dar cuenta al Pleno en la primera sesión que se celebre con posterioridad a la adopción de dichos acuerdos. De esta manera, se elimina cualquier posibilidad de debate político, de control de la acción del gobierno y, por tanto, se incide negativamente en el funcionamiento democrático del sistema de gobierno municipal.

No cabe duda de que unos de los aspectos más negativos de las Administraciones locales en los últimos años ha sido la proliferación de la Administración instrumental en las Corporaciones locales, en muchos casos reproduciendo de manera mimética los esquemas estatales y, por tanto, de manera tan poco adecuada a la realidad municipal. Al objetivo de «racionalizar» esas estructuras se dirige la Disposición Adicional 9a , la cual, bajo el título Redimensionamiento del sector público local,

56 Para ello establece una tabla en la que se usan como criterios el número de habitantes y la referencia de la retribución de un Secretario de Estado, a la que se van restando un determinado porcentaje de manera correlativa a la población de cada municipio. Para dar cumplimiento a lo previsto en dicho artículo, el Consejo de Ministros de 24 de enero de 2014 aprobó por Decreto-Ley una disposición adicional nonagésima en la Ley 22/2013, de 23 de diciembre, de Presupuestos Generales de Estado que viene a determinar el límite máximo total que pueden percibir como retribución los miembros de las Corporaciones Locales. Para que esta normativa pueda aplicarse desde la primera nómina a abonar en este 2014, su entrada en vigor será inmediata.

57 En relación a estas medias habría que tener en cuenta que no está claro que las mismas generen ningún tipo de ahorro, además que «una adecuada remuneración a los políticos es una condición imprescindible para conseguir reclutar para el cargo a los más capaces». BOSCH, N. y SOLÉ, A. «Una valoración preliminar de la reforma de la Administración local en España», www.ieb.ub.edu (consultada: 14/03/14), p. 17. 
prevé que las entidades locales y los organismos autónomos de ellas dependientes no podrán adquirir, constituir o participar en la constitución, directa o indirectamente de nuevos organismos, entidades, consorcios, fundaciones, unidades y demás entes durante el tiempo de vigencia de su plan económico-financiero o de su plan de ajuste ${ }^{58}$. En cuanto a las existentes que se encuentren en situación deficitaria se les exige su saneamiento y, si éste no se produce con fecha de 31 de diciembre de 2014, se deberá proceder a su disolución. Además se prohíbe, en todo caso, la creación de entidades instrumentales de segundo nivel, es decir, unidades controladas por otras, que a, su vez, lo estén por las Entidades locales. Se introducen medidas dirigidas a la racionalización organizativa e integración coordinada de servicios que deberán incluirse en los planes económico-financieros de los Entes locales junto las ya previstas en el Art. 21 de la LO 2/2012, de 27 de abril.

2. ${ }^{\text {a }}$ Un conjunto de medidas, de dudosa efectividad práctica, de fomento de la fusión voluntaria de municipios, tales como el incremento de su financiación, la preferencia en la asignación de planes de cooperación local o subvenciones, o la dispensa en la prestación de nuevos servicios obligatorios como consecuencia del aumento poblacional (art. 13) ${ }^{59}$. Además, si se acordara entre los municipios

58 «Lo que parece claro es que quiere evitarse que continúe el crecimiento descontrolado del sector público instrumental local, reconduciendo —o quizás constriñendo — la potestad de autoorganización de los entes locales a los márgenes, estrictamente económicos derivados de su capacidad y suficiencia financiera. No obstante, también parece evidente que la simple reducción del gasto fijo de determinadas organizaciones instrumentales —aunque en algún caso con un volumen más que considerable — no tiene porqué repercutir inmediata y sensiblemente en el equilibrio financiero global de la entidad territorial de referencia (...) Las medidas de redimensionamiento y reorganización de las estructuras locales deben combinarse, en todo caso, con procesos estructurales de renovación procedimental, simplificación y agilización ( a través por ejemplo de la Administración electrónica) de la toma de decisiones y de los instrumentos de gestión, ponderación — cualitativa y cuantitativa — de las medidas de intervención, racionalización —y cumplimiento - de los programas de actuaciones, etc.» MELLADO RUIZ, L. «Notas sobre el anteproyecto de ley...», cit., p. 17.

59 Esta apuesta contrasta por ejemplo con las conclusiones a las que se llegaron sobre la reforma de la planta local en el VIII Congreso de la Asociación Española de Profesores de Derecho Administrativo: «No hay acuerdo en que la causa principal de los actuales problemas de estabilidad presupuestaria, de sostenibilidad financiera y de déficit público en el ámbito local sea el inframunicipalismo y, en general, la Planta Local. Es más, hay serias dudas a la hora de cuantificar la deuda local y su incidencia proporcional en el conjunto estatal, y aún es menos claro que esa deuda sea imputable precisamente a los pequeños municipios. Sí, en cambio, hay acuerdo en que han incidido en ello las consecuencias de una hacienda local excesivamente basada en ingresos patrimoniales y fiscales vinculados a la actividad urbanística». Junto a ello, tampoco se llegó a un acuerdo en torno a si las fusiones generalizadas de municipios, como las efectuadas en otros contextos europeos, sean la solución adecuada para España: «Por un parte, porque las condiciones demográficas y territoriales de partida son bien distintas y, por otra parte, en cuanto a los efectos producidos en esos países, porque no se han comprobado aún los beneficios obtenidos en cuanto a la eficiencia y, en cambio, sí se han constatado ya algunas consecuencias negativas en cuanto a pérdida de representatividad democrática y de articulación social». Recogidas por T. FONT y A. GALÁN en «Racionalización y sostenibilidad de la Administración local...», cit., pp. 26 y 27. En un sentido contrario se pronuncian por ejemplo N. BOSCH y A. SOLÈ que apuestan por la reducción del número de municipios a través de fusiones que llevarán a alcanzar un tamaño mínimo de 5000 habitantes y, a ser posible, acercarse a los 10.000. Su propuesta llevaría a un proceso participado en el que el Estado proporcionaría incentivos financieros para una fusión voluntaria rápida que, pasado el tiempo, se haría obligatoria. Las CCAA se encargarían de organizar el proceso de delimitación de los nuevos municipios. «Una valoración preliminar de la reforma...», cit., p. 17. 
fusionados alguno de ellos podría funcionar como forma de organización desconcentrada, lo que permitiría conservar la identidad territorial y denominación de los municipios fusionados aunque pierdan su personalidad jurídica ${ }^{60}$.

Con respecto a la creación de nuevos municipios, el art. 13.2 dispone que solo podrá realizarse sobre la base de núcleos de población territorialmente diferenciados, de al menos 5.000 habitantes y siempre que los municipios resultantes sean financieramente sostenibles, cuenten con recursos suficientes para el cumplimiento de las competencias municipales y no suponga disminución en la calidad de los servicios que venían siendo prestados ${ }^{61}$.

3. ${ }^{a}$ El art. 86 limita la iniciativa pública de las entidades locales para el desarrollo económico a aquellos supuestos en los que esté garantizado el cumplimiento del objetivo de estabilidad presupuestaria y de la sostenibilidad financiera del ejercicio de sus competencias. Se exige que en el expediente acreditativo de la conveniencia y oportunidad de la medida se justifique que la iniciativa no genera riesgo para la sostenibilidad financiera del conjunto de la Hacienda municipal. La LRSAL obliga a incluir un análisis del mercado, relativo a la oferta y demanda existente, a la rentabilidad y a los posibles efectos de la actividad local sobre la concurrencia empresarial. Aunque el apartado 2 del artículo reserva a favor de las Entidades locales una serie de actividades o servicios esenciales, se permite que el Estado y las Comunidades Autónomas, en el ámbito de sus respectivas competencias, puedan establecer mediante ley idéntica reserva para otras actividades y servicios. De acuerdo con estas previsiones, «no es solo que la iniciativa pública económica se convierta en prácticamente «subsidiaria», sino que la aplicación estricta de estos criterios podría conducir a hacer ilusoria la capacidad local de intervención económica —reconocida, para cualquier Administración, en el texto constitucional, ex art. 128.2 CE» ${ }^{62}$.

60 Como señala la Exposición de Motivos, este tipo de medidas encuentran respaldo en la jurisprudencia constitucional más reciente, aludiendo en concreto a la STC 103/2013, de 25 de abril, que resolvió el recurso de inconstitucionalidad que planteó el Parlamento de Cataluña contra diversos preceptos de la Ley 57/2003, de 16 de diciembre, de medidas para la modernización del gobierno local. En todo caso, esta clara apuesta por la fusión parece desconocer que «la supresión jurídica de ayuntamientos y la consiguiente eliminación institucional del municipio no alivian los costes en la provisión de servicios públicos». ZAFRA VÍCTOR, M. «Autonomía local en el Estado autonómico», cit., p. 550. Además de que la misma supone en definitiva «un menoscabo del pluralismo político y, por tanto, un empobrecimiento de la democracia». ZAFRA VÍCTOR, M. «La provincia...», cit., p. 67.

61 Estas previsiones plantean muchas dudas en cuanto a su incidencia en las competencias autonómicas sobre demarcación municipal. Si bien, por ejemplo, el art. 91 EAA reconoce que la alteración de términos municipales ha de producirse «en el marco de la legislación básica del Estado», estamos ante una de esas materias que progresivamente se ha ido «interiorizando» en el ámbito autonómico. De esta manera, es fácil detectar una colisión entre las previsiones tan estrictas que realiza el legislador básico estatal y las que han realizado legisladores autonómicas. Piénsese por ejemplo como la LAULA sitúa la competencia sobre demarcación municipal en el Consejo de Gobierno autonómico (art. 90), además de insistir en que «corresponde en exclusiva a la Junta de Andalucía la competencia para efectuar las modificaciones de términos municipales en su territorio» (art. 90.3).

62 MELLADO RUIZ, L. «Notas sobre el anteproyecto de ley...», cit., pp. 29-30. En el mismo sentido, se pronuncia F. VELASCO que insiste en la posible afectación del art. 128.2 CE, al quedar relegada la iniciativa económica municipal a un segundo plano. «Nuevo régimen de competencias...», cit., p. 44. 
4. ${ }^{a}$ La ley introduce también un nuevo régimen de la cooperación entre la Administración local y las del Estado y de las Comunidades Autónomas. De acuerdo con los principios rectores de la LRSAL, el nuevo art. 57 dispone que la suscripción de convenios y consorcios debe realizarse con el objetivo de «mejorar la eficiencia de la gestión pública, eliminar las duplicidades administrativas y cumplir con la legislación de estabilidad presupuestaria y sostenibilidad financiera». Además los consorcios se contemplan de manera subsidiaria a los convenios, de forma que aquellos solo podrán constituirse «cuando la cooperación no pueda formalizarse a través de un convenio y siempre que, en términos de eficiencia económica, aquella permita una asignación más eficiente de los recursos económicos. En todo caso, habrá de verificarse que la constitución del convenio no pondrá en riesgo la sostenibilidad financiera del conjunto de la Hacienda de la Entidad Local de que se trate, así como del propio consorcio, que no podrá demandar más recursos de los inicialmente previstos» (art. 57.3)

5. ${ }^{a}$ Con el objetivo de lograr un control económico-presupuestario más riguroso, se refuerza el papel de la función interventora en las entidades locales (nueva redacción de los artículos 213 y 218 del Texto Refundido de la Ley Reguladora de las Haciendas Locales, RD Legislativo 2/20014, de 5 de marzo). Para ello, el Gobierno fijará las normas sobre los procedimientos de control, metodología de aplicación, criterios de actuación, así como derechos y deberes en el desarrollo de las funciones públicas necesarias en todas las Corporaciones locales ${ }^{63}$.

\section{CONCLUSIONES}

1. La LRSAL supone un significativo paso adelante en la configuración de los Ayuntamientos como meros prestadores de servicios y en su devaluación como entidades articuladas constitucionalmente sobre los principios de autonomía y democrático. En este sentido, hay una clara negación del contenido que a la autonomía local se le otorga en la Carta Europea de Autonomía local. Con la actual reforma queda en entredicho su «garantía constitucional» ${ }^{64}$, la cual debería proyectarse

63 Como se ha señalado, no parece ser que estas previsiones resuelvan los problemas que afectan a los interventores en el ámbito municipal, los cuales derivan del hecho de que «su designación, sueldo e incluso régimen disciplinario (en algunas CCAA) está en manos de los políticos locales. En algunos casos, la situación es incluso peor, puesto que el puesto está ocupado por un interino que puede ser incluso un técnico no habilitado... Algunos Ayuntamientos evitan sacar a concurso las plazas, puesto que los políticos prefieren lidiar con técnicos designados directamente por ellos. Otros Ayuntamientos (los más pequeños) no pueden cubrir las plazas por falta de candidatos, puesto que no se convocan oposiciones y la escasez de habilitados hace que los elevados sueldos que se están pagando sean inasumibles para estos municipios. En algunos Ayuntamientos pequeños se dispone de un Secretario-Interventor, con lo que la persona encargada de gestionar es la misma que la encargada de fiscalizar, una situación desde luego algo esquizofrénica. Esta situación hace que el Ayuntamiento bien carezca completamente de un controlador financiero, bien que la independencia del mismo esté condicionada por el poder político». BOSCH, N. y SOLÉ, Albert. «Una valoración preliminar...», cit. , p. 17.

64 Prefiero usar ese término al de «garantía institucional», tal y como ha hecho buena parte de la doctrina. Véase por ejemplo J. GARCÍA MORILLO, La configuración constitucional de la autonomía local, Marcial Pons, Diputaciò de Barcelona, 1998, p. 138; o J. GARCÍA ROCA, «Un bloque constitucional local conforme al principio de subsidiariedad (desarrollo constitucional pendiente)», cit., p. 24. 
en un doble contenido: por una parte, los arts. 137, 140 y $141 \mathrm{CE}$ garantizan de forma inmediata y directa (a cada municipio, provincia e isla) un «mínimo de autonomía local»; de otra, imponen a todos los poderes públicos (cada uno en la esfera de su competencia) la elevación de esos mínimos de esa autonomía local al «máximo de lo posible» ${ }^{65}$. Parece más que evidente que, en este caso, el «mínimo» se vulnera en algunos supuestos y el «máximo» queda frenado. Todo ello en nombre no tanto del equilibrio presupuestario, sino más bien desde el objetivo de suprimir el gasto local y por lo tanto condicionar el ámbito de actuación política de los municipios ${ }^{66}$.

2. Al mismo tiempo muchas de sus previsiones suponen una clara intromisión del Estado en las competencias autonómicas sobre régimen local y una ruptura con el modelo de progresiva interiorización de dicho régimen en las Comunidades Autónomas ${ }^{67}$. Como bien ha señalado Manuel Zafra, «los títulos competenciales del Estado no autorizan a delimitar en positivo las competencias autonómicas, si así fuera, fraudulentamente, el legislador estatal habría cruzado el umbral del legislador de armonización incumpliendo las exigencias constitucionales del artículo $150.3 »^{68}$. De esta manera, el legislador estatal parece desconocer la doctrina que se había ido consolidando por parte del Tribunal Constitucional a partir de la sentencia 240/2006, de 20 de julio, la primera dictada en un conflicto en defensa de la autonomía local. En ella el Constitucional relativizó

65 VELASCO CABALLERO, F., «Estatutos de autonomía, leyes básicas y leyes autonómicas en el sistema de fuentes del Derecho local», Anuario de Gobierno Local, 2006, p. 126.

66 VELASCO CABALLERO, F. «Nuevo régimen de competencias municipales en el Anteproyecto...», cit. p. 26.

67 Así se pone de manifiesto en los diversos recursos de inconstitucionalidad planteados por varias CCAA (Andalucía, Extremadura, Cataluña, Navarra, Canarias, Asturias), los cuales se suman al interpuesto por varios grupos parlamentarios del Congreso. A ello hay que sumar la reacción «defensiva» que frente a la Ley ha adoptado la Junta de Andalucía mediante la aprobación de un Decreto-Ley en el que blinda las competencias municipales para garantizar los servicios más cercanos a la ciudadanía frente a la revisión que en dicha materia plantea la LRSAL. En concreto, el Decreto-Ley 7/2014, de 20 de mayo, por el que se establecen medidas urgentes para la aplicación de la Ley 27/2013, parte de considerar que «las competencias atribuidas a las entidades locales de Andalucía por las leyes anteriores a la entrada en vigor de la ley 27/2013, de 27 de diciembre, de racionalización y Sostenibilidad de la Administración local, se ejercerán por las mismas de conformidad a las previsiones contenidas en las normas de atribución, en régimen de autonomía y bajo su propia responsabilidad, de acuerdo con lo establecido en el artículo 7.2 de la ley 7/1985, de 2 de abril, reguladora de las Bases del régimen local, todo ello sin perjuicio de lo dispuesto en los artículos siguientes del presente Decreto-ley» (art.1). Entre otras previsiones, su DA $1^{a}$ establece que «las competencias que, con carácter previo a la entrada en vigor de la ley 27/2013, de 27 de diciembre, se preveían como propias de los municipios en materia de participación en la gestión de la atención primaria de la salud e inspección sanitaria, en materia de prestación de servicios sociales, y de promoción y reinserción social, así como aquellas otras en materia de educación, a las que se refieren las disposiciones adicionales decimoquinta y transitorias primera, segunda y tercera de la ley 27/2013, de 27 de diciembre, continuarán siendo ejercidas por los municipios en los términos previstos en las leyes correspondientes, en tanto no hayan sido asumidas por parte de la comunidad Autónoma.»

68 ZAFRA VÍCTOR, M., «Esta reforma local empobrece la democracia», cit. En el mismo sentido véase F. SILVA ARDANUY, «Estatutos de autonomía de "segunda generación; competencias exclusivas frente al Proyecto de Ley de Racionalización y Sostenibilidad de la Administración Local», Lex Social, Revista jurídica de los Derechos Sociales, vol. 4, $\mathrm{n}^{\circ} 1 /$ enero-junio 2014, p. 86. 
el papel de la LBRL como garante de la autonomía local frente al legislador, al estimar que la misma no se integra en el bloque de la constitucionalidad y que por tanto sólo podría actuar como canon de validez de la ley autonómica «en aquellos aspectos enraizables directamente en los artículos 137, 140 y $141 \mathrm{CE}$ » Si como señaló Manuel Zafra, dicha sentencia «deconstitucionaliza la LBRL» ${ }^{69}$, podríamos afirmar que la LRSAL vuelve a «constitucionalizarla» en nombre de la sostenibilidad financiera. De esa manera, los «niveles básicos» de autonomía local, que son los que debe fijar el Estado en virtud del art. 149.1.18 CE, se convierten en un «obstáculo» para la capacidad de las Comunidades autónomas en orden a fijar el «nivel final» de la autonomía de los municipios y las provincias, además de contravenir en muchos casos los «niveles más elevados» fijados por la Carta Europea de Autonomía Local ${ }^{70}$.

3. La ley no soluciona la que debería ser la cuestión clave de acuerdo con los objetivos de estabilidad presupuestaria que se persiguen cual es la financiación municipal, la cual, a su vez, debería ser regulada teniendo presente el marco de la financiación autonómica. En este sentido, deja sin resolver la necesaria definición de un marco competencial propio de las entidades locales y la consiguiente financiación de carácter incondicionado ${ }^{71}$. A todo ello habría que sumar las dificultades técnicas que sin duda plantearán la aplicación de muchas de sus previsiones.

4. La LRSAL vuelve a demostrar que nuestros gobernantes siguen sin «tomarse en serio» la autonomía local, es decir, sin considerarla como un pilar más de la estructura territorial del Estado, articulado sobre los principios de «autonomía» y «democrático». Pese a los «buenos propósitos» que animan el texto, o tal vez precisamente por ellos, me temo que la reforma no pasa de ser una respuesta coyuntural y no la reforma en profundidad que requeriría nuestro régimen local. En

69 ZAFRA VÍCTOR, M. «Garantía estatutaria de la autonomía local», Anuario de Gobierno Local 2008, 2009, p. 43.

70 Sigo el a mi parecer acertado criterio de Francisco Velasco que distingue entre los niveles mínimos de autonomía local (que serían los fijados por la Constitución), los más elevados (Carta Europea de Autonomía Local), los básicos (LBRL) y el nivel final que correspondería a los Estatutos y leyes autonómicas. «El gobierno local en la reforma de los Estatutos: Estatutos de autonomía, leyes básicas y leyes autonómicas en el sistema de fuentes del Derecho Local», Anuario de Derecho Local 2005, 2006, p. 128

71 Además de superar las subvenciones condicionadas, debería regularse de una vez por todas la participación de los entes locales en los tributos de las CCAA. Algo que la FEMP ha venido denunciado de manera permanente ya que afecta a la garantía del principio de suficiencia financiera de las Entidades locales. Ello obligaría a una reforma de la actual Ley de Haciendas Locales, así como en menor medida de la Ley Orgánica de Financiación de las Comunidades Autónomas. Por otra parte, la financiación local debería tener presentes las grandes diferencias intermunicipales tanto en las bases imponibles de los tributos municipales - la denominada «capacidad fiscal»— como en las necesidades de gasto de los servicios locales. Estas diferencias se traducen irremediablemente en diferencias de calidad de los servicios públicos. Para subsanarlas, más que como hace la LRSAL limitar la capacidad de algunos municipios, sería conveniente que las transferencias que reciben se distribuyesen de forma directamente proporcional a las necesidades de gasto de los municipios e inversamente proporcional a su capacidad fiscal. De esta manera, recibirían más recursos los municipios con menor capacidad fiscal y con mayores necesidades. SOLÉ OLLÉ, A. «Economía política de los gobiernos locales. Una valoración del funcionamiento de los municipios», Actualidad, Centro de Estudios Andaluces, $\mathrm{n}^{\circ} 15,2007$, p. 13. 
este sentido, parece más que evidente que «no siempre la "racionalización” conlleva "racionalidad" ${ }^{72}$.

La necesaria reforma del régimen local debería plantearse en el marco de un acuerdo territorial en el que participen Estado, Comunidades autónomas y entes locales. Un acuerdo que pasaría necesariamente por tres aspectos —competencias, financiación, estructura organizativa- y que, siendo tal vez demasiado optimistas, debería plasmarse en un pacto de Estado y en la consiguiente reforma del Título VIII de la Constitución. Una reforma en la que como mínimo deberían contemplarse tres cuestiones ${ }^{73}$ : a) La definición de la autonomía local como una competencia compartida entre el Estado y las CCAA; b) La habilitación a una Ley Orgánica de bases de gobierno y administración local, de la que se subraye su «función constitucional» de desarrollo y concreción de la autonomía local. Dicha Ley debería concretar el contenido «mínimo» de la autonomía local, mientras que el legislador estatutario establecería el contenido «óptimo» para su propio territorio; c) La introducción de los principios básicos que recoge la CEAL, fundamentalmente los de subsidiariedad, proporcionalidad y diferenciación.

Comparto la idea de que «la solución a una mayor descentralización local... debe ser el resultado de un cambio sustancial de cultura que oriente la actuación de los poderes públicos hacia el nivel más próximo al ciudadano, siguiendo criterios de subsidiariedad, de eficacia, de gestión integrada y cooperativa, de capacidad y sostenibilidad ${ }^{74}$. A ello sumaría los objetivos ineludibles de mayor calidad democrática y el horizonte de justicia que supone garantizar el máximo nivel de bienestar de la ciudadanía. Es decir, no debería perderse de vista que el objetivo principal de cualquier reforma de las Administraciones públicas debiera tener presente el objetivo de responder de manera más eficaz y justa a las necesidades ciudadanas, poniendo las bases organizativas y jurídicas para que sus condiciones de vida, la satisfacción de sus derechos y en general la convivencia superaran los obstáculos vigentes. Todo ello sin perder de vista la racionalidad democrática que debería fundamentar y orientar cualquier cambio sustancial en los espacios públicos. En este sentido no cabe duda de que la LRSAL es una muestra más de la involución que está representando, bajo el pretexto de la crisis económica, «la progresiva limitación de las condiciones formales y materiales que habían conformado hasta ahora a las democracias pluralistas y el debilitamiento de la normatividad de la Constitución». Una situación ante la que habría que responder, también en lo relativo a la auto-

72 MELLADO RUIZ, L. «Notas críticas sobre el Anteproyecto de Ley para la racionalización y sostenibilidad de la Administración local: entre la reforma y la intervención», cit., p. 2.

73 Comparto plenamente las propuestas de J. GARCÍA ROCA en «La primera sentencia constitucional sobre el conflicto en defensa de la autonomía local (STC 240/2006): una ocasión perdida», Cuadernos de Derecho Local, no 14,2007 , p. 23.

74 ARENILLA SÁEZ, M. «Centralización vs. Descentralización», Revista Democracia y Gobierno Local, $\mathrm{n}^{\circ}$ 23, 2013, p. 15. El Catedrático de la Carlos III, actualmente director del INAP, concluye que «la nueva ley local viene a remover la distribución actual de ese poder» y coloca la «piedra» en el «tejado de los poderes centrales y autonómicos en cuanto a la satisfacción de dichos objetivos. Un diagnóstico, y en consecuencia una conclusión, que no comparto. 
nomía local, revitalizando la normatividad de la Constitución y recuperando los principios de una democracia pluralista ${ }^{75}$.

De momento esos retos permanecen frustrados ante una reforma que no es la que esperábamos muchos de los que seguimos creyendo en el municipalismo como sostén de la democracia, ni la que contribuirá a conseguir unos entes locales que se ajusten mejor a las exigencias de la nueva realidad tan compleja que habitamos. Sobre todo porque la clave no debería ser la desconfianza hacia el mundo municipal que pone de manifiesto esta ley sino más bien su adaptación a los factores sociales y políticos que reclaman una nueva manera de gestionar lo público y de satisfacer las demandas de la ciudadanía.

$$
* * *
$$

TITLE: The devalued local autonomy: The questionable rationality of Law 27/2013, of 27 December, of rationalization and sustainability of local government

ABSTRACT: Law 27/2013, of 27 December, of rationalization and sustainability of local government has been a step in the fragile local autonomy guaranteed in our constitutional system. The reform, which responds to the demands of sustainability to rationalization, attentive not only against local autonomy but also against the competence of the Comunidades Autónomas. While left unresolved the central question that is none other than the location of the local authorities in the territorial structure and especially its financing.

Resumen: La Ley 27/2013, de 27 de diciembre, de racionalización y sostenibilidad de la Administración local ha supuesto un paso más en la frágil garantía de la autonomía local en nuestro sistema constitucional. La reforma, que responde más a las exigencias de sostenibilidad que a las de la racionalización, atenta no solo contra la autonomía local sino también contra el ámbito competencial de las Comunidades Autónomas. Al tiempo que deja sin resolver la cuestión esencial que no es otra que la ubicación de los poderes locales en la estructura territorial y especialmente su financiación.

KEY wORDs: local autonomy, rationalization, sustainability, democracy, Comunidades autónomas.

Palabras clave: Autonomía local, racionalización, sostenibilidad, democracia, Comunidades Autónomas.

FECHA DE RECEPCIÓN: 28.05.2014 FeCHA DE ACEPTACIÓN: 30.07.2014

75 BALAGUER CALLEJÓN, F. «Una interpretación constitucional de la crisis económica», Revista Española de Derecho Constitucional Europeo, n ${ }^{\circ} 19$, enero-junio 2013, pp. 449-454. 